\title{
GENERALIZAÇÃO CARTOGRÁFICA APLICADA À REPRESENTAÇÃO DE REDES SOCIAIS
}

\section{Cartographic Generalization applied to Social Networks Representation}

\author{
RENAN MARTINS POMBO \\ CLAUDIA ROBBI SLUTER \\ Universidade Federal do Paraná \\ Setor de Ciências da Terra - Departamento de Geomática \\ Programa de Pós-Graduação em Ciências Geodésicas \\ Caixa postal 19.001 - Jardim das Américas \\ Curitiba - PR - Brasil. \\ renanpombo@gmail.com; robbi@ufpr.br
}

\begin{abstract}
RESUMO
O termo rede é usado em várias áreas do conhecimento, com diversas acepções e diferentes aplicações. Nas ciências sociais estudam-se as redes sociais que abrangem pessoas, grupos e instituições, chamados de nós, que se interligam. Nestas redes os atores são representados por nós e suas relações por linhas. A apresentação destas redes pode ser feita por grafos, sem referência espacial. Com o conhecimento da posição geográfica dos atores estes podem ser inseridos em mapas, que apoiados sobre uma base cartográfica referenciam espacialmente a rede social. O objetivo deste trabalho é representar digitalmente estas redes sociais em uma tela de um monitor de 15 polegadas. Como a área de representação é pequena ocorrem problemas de comunicação como o congestionamento de símbolos. Este problema foi resolvido com a aplicação da generalização cartográfica da qual valeram-se dos operadores agregação, deslocamento e suavização. Os resultados mostram que os mapas generalizados são mais eficazes no processo de comunicação.
\end{abstract}

Palavras-chave: Redes Sociais; Representação de Redes Sociais; Generalização de Redes.

\section{ABSTRACT}

The term network is used in many areas of knowledge, with different meanings and different applications.In the social sciences, are studied social networks that may 
consist of individuals, groups and institutions, called nodes, which are interconnected are studied. In these networks, the actors are represented by nodes and their relations by lines. The representation of these networks can be done using graphs, without spatial reference. With the knowledge of the geographical position of the actors, they can be placed on maps with a base map that provides spatial reference to the social network. The objective is to represent these social networks in a 15-inch monitor screen. With the reduction in area of representation, communication problems such as congestion of symbols may occur. This problem was solved with the application of cartographic generalization operators such as aggregation, displacement and smoothing. The results show that the generalized maps are more effective in the communication process.

Keywords: Social Networks; Representation of Social Networks; Network Generalization.

\section{INTRODUÇÃO}

Rede social é uma das formas de representação dos relacionamentos afetivos ou profissionais entre si ou entre seus agrupamentos de interesses mútuos. Genericamente, as redes sociais são compreendidas como um conjunto de atores sociais (pessoas, grupos e instituições), chamados de nós, que se interligam quando há relações entre si, e que integram um sistema social. O conjunto das relações dentro deste sistema pode ser representado por uma rede, por exemplo, por meio de um conjunto de pontos, total ou parcialmente, interligados (DELAZARI, SLUTER e KAUCHAKJE,2007).

Segundo Matheus e Silva (2006), a análise de redes utiliza modelagem matemática, especialmente por meio de grafos. Uma rede não tem centro, mas sim nós de diferentes dimensões e relações internodais, de forma que todos os nós são necessários para a existência da rede. A análise de redes objetiva mostrar que a própria forma da rede explica a maneira como e porque os fenômenos observados acontecem. Minella (2008) assinala que a análise de redes pode ser aplicada em diversos campos do conhecimento com diferentes enfoques dependendo do tipo de situação, como por exemplo, em estudos de movimentos sociais, relações internacionais, elites políticas e econômicas, políticas públicas, organizações empresariais, classes sociais, produção de conhecimentos e meios de comunicação.

Os programas computacionais utilizados pelos cientistas sociais não representam as redes por suas localizações espaciais e pelos atributos de suas relações, mas somente um aglomerado de nós ligados entres si ou não sem as suas posições geográficas. Este papel compete à Cartografia por meio do mapeamento temático. A visualização cartográfica aplicada às redes sociais pode contribuir com um aprofundamento do caráter exploratório das análises das redes.

A rede social abordada neste trabalho está atrelada ao sistema de proteção social que garante o direito à assistência social da cidade de Curitiba, estado do Paraná. As entidades vinculadas a este sistema podem ou não estar localizadas em 
Curitiba, pois há casos em que as entidades que atuam no município têm sua sede em outros municípios ou estados.

Marchis (2008) propôs em seu trabalho um projeto cartográfico para representação de redes sociais. $\mathrm{O}$ qual foi considerado eficiente por cientistas sociais. Os mapas foram feitos de modo a representar todos os atores sociais de cada rede abordada sem que houvesse sobreposição entre eles. No trabalho de Marchis (2008) foi definida a escala de 1:75.000 e os mapas podem ser impressos em papel de formato A0.

Nesta pesquisa foram utilizados mapas digitais que pudessem ser visualizados em um monitor de 15 polegadas. Como a área de representação é menor a escala precisou ser reduzida, e, para evitar problemas de comunicação com o mapa foram aplicados os conceitos de generalização cartográfica. As características geográficas e estruturais da rede devem ser combinadas nos mapas temáticos de maneira a se obter uma representação que atenda às necessidades do usuário, seja qual for a escala utilizada. Recorreu-se à generalização cartográfica por esta ter o papel de abstrair e simplificar as informações cartográficas de acordo com a sua importância e contribuição para o uso do mapa (NALINI, 2005).

Com a distribuição espacial será possível conhecer a existência de concentrações e de ausências de atores em determinadas regiões, o que permite verificar e entender porque determinadas regiões são melhores assistidas do que outras, ou a possibilidade de novos atores instalarem-se em regiões desprovidas de um determinado serviço.

Quando se analisa as ligações entre os atores, considerando a espacialização geográfica, o usuário poderá visualizar as ligações e as distâncias envolvidas entre eles. Verificar as relações entre as centralidades e a alta concentração de ligações de alguns atores, o que permitirá saber quais são os atores significativos e os mais influentes, de modo que possibilite o entendimento de sua importância no contexto espacial. Portanto a representação cartográfica de uma rede social aprofunda o conhecimento do analista. Assim, o objetivo geral deste trabalho é representar as características geográficas de uma rede social juntamente com seus aspectos topológicos para ampliar o poder de análise dos usuários. Porém desta vez utilizando uma área de representação menor o que implica numa redução da escala e faz-se a necessidade da aplicação generalização cartográfica.

\section{ANÁLISE E REPRESENTAÇÃO DE REDES SOCIAIS}

Há conceitos simples para rede como, por exemplo, um entrelaçado de tecido, além de conceitos complexos como a ligação entre computadores de todo o mundo. Loiola e Moura (1997) identificam diversas definições de rede, partindo da noção de entrelaçamento de fios e formação da malha e de sua analogia com as concepções nas ciências tecnológicas, organizacionais e sociais, passando por outros sentidos, que incluem armadilha, instrumento de proteção, instrumento de 
sustentação e marco divisório entre concorrentes. O conceito também representa a ideia de fluxo e de circulação, tais como redes de comunicação, de transportes, entre outras.

Nas ciências sociais, as redes são estruturas multicêntricas que compreendem diferentes atores, organizações ou nós, ligados entre si a partir do estabelecimento e manutenção de objetivos comuns e de uma dinâmica gerencial compatível e adequada (FLEURY, 2004).

As análises de redes sociais enfatizam as relações entre os atores, o que significa que estes normalmente não são amostrados independentemente, como no caso de outros tipos de dados convencionais que focalizam nos atores e nos atributos. O estudo das redes complexas foi iniciado pelas ciências exatas e, em seguida, promovido pela sociologia, numa perspectiva de análise estrutural das redes sociais que com suas representações revelam padrões (TOMAEL, 2006).

A informação coletada sobre as relações entre os atores de uma rede é definida segundo diferentes níveis de medida. Pode-se medir desde o grau de centralidade até identificar o tipo de parceria entre os atores. Os analistas de redes sociais utilizam duas formas para representar a informação: grafos (sociogramas) e matrizes (TOMAÉL, 2006).

Existem vários tipos de grafos, porém os analistas sociais utilizam um tipo específico que consiste em pontos (ou nós) que representam atores e em linhas, para representar laços ou relações. Este tipo de grafo é denominado pelos sociólogos de sociograma (HANNEMAN, 2001). A Figura 1 mostra um exemplo de sociograma que trata de um grafo direcionado. Quando a seta possui dois sentidos caracteriza uma relação recíproca. No caso de haver apenas um sentido a relação não é recíproca, e se não há um segmento de reta, não há ligação.

Figura 1 - Grafo direcionado.

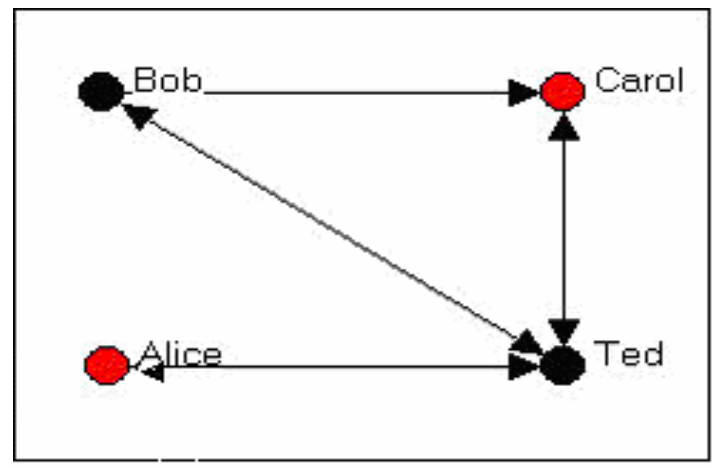

Bol. Ciênc. Geod., sec. Artigos, Curitiba, v. 16, nº 3, p.445-455, jul-set, 2010. 


\section{PROJETO CARTOGRÁFICA E GENERALIZAÇÃO CARTOGRÁFICA}

A metodologia estabelecida para o desenvolvimento desta pesquisa engloba o projeto e a produção de mapas temáticos por meio da visualização e da generalização cartográfica para o sistema de proteção social, que garante o direito à assistência social da cidade de Curitiba. Faz-se uso da generalização cartográfica nestes mapas devido à nova área de representação, que é a tela do computador, então, a escala será bastante reduzida, uma vez que os mapas originais foram construídos em papel de formato A3.

\subsection{Definição das Escala de Análise e do Sistema de Projeção}

Os mapas municipais foram elaborados na escala de 1:230.000. A rede social a ser analisada tem suas ações voltadas ao sistema de proteção social e de direito à assistência social na cidade de Curitiba.

Os mapas que abrangem o município de Curitiba foram elaborados no sistema de referência SAD-69 e no sistema de projeção UTM, fuso 22. É nessa zona que se localiza a maior parte do estado do Paraná, incluindo a cidade de Curitiba .

\subsection{Definição das Informações Temáticas e Generalização Conceitual}

As informações temáticas definidas para este projeto cartográfico são os atores sociais formadores da rede, as suas ligações e os seus atributos. Estes atributos devem fornecer informação a respeito do tipo de organização em que o ator em questão se enquadra. Além disso, deve ser evidenciado o número de ligações de cada ator, bem como as características dessas relações. E também, os dados devem conter informações acerca da importância de cada nó para a rede, ou seja, os valores de centralidade.

Estas informações foram generalizadas por meio da classificação, que foi o único operador de generalização conceitual utilizado nesta pesquisa. Os tipos de organizações foram classificados por meio do critério do vínculo com o governo em qualquer esfera. Quando ocorria o vínculo, a organização era classificada como governamental. Caso contrário era classificada como não-governamental, movimento social ou outros. Pelo fato de as ONGs (Organizações NãoGovernamentais) terem características muito diversas, foi necessário subclassificálas nas seguintes classes: confessional, movimentalista, filantrópica, empresarial, ligada ao estado e outros.

Estas classificações dos nós têm um nível de medida nominal, assim como os tipos de ligações entre si. Estas foram classificadas em três classes: apoio/colaborador, parceiros temáticos, e parceiros por projeto.

Outra característica levantada a respeito dos atores foi a centralidade de grau, que mostra o número de ligações que cada ator possui com outros atores. Tal informação tem uma escala de medida numérica, e foi classificada por meio do método de Jenks. 


\subsection{Coleta dos Dados}

As bases cartográficas estadual e nacional foram conseguidas gratuitamente no site do IBGE no ano de 2008. Quanto a base do município de Curitiba, foi obtida junto ao IPPUC (Instituto de Pesquisa e Planejamento Urbano de Curitiba).

As informações acerca dos atores sociais foram obtidas a partir de pesquisas realizadas nos sites de busca da internet. A maioria das instituições possui página na internet e com a análise obtiveram-se os dados sobre as suas relações com outras entidades. Após organizar todas as informações levantadas, permitiu criar os bancos de dados dos shapefiles usados na produção dos mapas temáticos. Esta organização se deu seguindo as classificações estabelecidas pela generalização conceitual.

\subsection{Generalização Geométrica}

Se ao alterar a escala do mapa e se nesta mudança houver uma modificação na comunicação cartográfica, ou seja, se existir a possibilidade do usuário tirar conclusões erradas devido à má representação, então é caracterizado o momento de realizar a generalização gráfica.

McMaster e Shea (1992) denominam este momento em seu modelo conceitual como avaliação cartométrica, que é pautada em três aspectos: condições geométricas, medidas espaciais e globais, e controle das transformações. As condições geométricas abrangem as situações geométricas advindas da redução de escala, na qual ocorrem problemas como: congestionamento, coalescência, conflito, complicação, inconsistência e imperceptibilidade. Para cada situação deve ser usado um ou mais operadores de generalização gráfica. Durante a produção dos mapas deste trabalho ocorreram problemas de congestionamento e imperceptibilidade. Para solucioná-los utilizaram-se, principalmente, os operadores agregação e deslocamento.

As medidas espaciais e globais (holísticas) têm a função de quantificar a grandeza que permite identificar uma condição geométrica. Isto é feito por meio da determinação dos relacionamentos entre as feições. Estas medidas são tidas como o ponto de partida para as discussões a respeito das condições geométricas. McMaster e Shea (1992) propõem as seguintes medidas: densidade, distribuição, comprimento e sinuosidade, forma e distância. Nesta pesquisa os operadores de generalização usados foram os de agregação, deslocamento, suavização e rotação. Estes resolverem os problemas de caolescência, congestionamento e imperceptibilidade.

Na Figura 2 mostra-se que a agregação foi utilizada quando os símbolos pontuais de mesma classificação se sobrepunham. O resultado desta operação foi a criação de um novo símbolo pontual, ao qual foi aplicada a variável visual tamanho proporcionalmente aonúmero de atores que este símbolo representava. Quando havia a coalescência entre símbolos pontuais de diferentes classificações aplicou-se o operador de deslocamento. A mudança de posicionamento dos atores não deveria alterar as orientações e posições relativas em relação aos demais atores. 
Figura 2 - Ação dos Operadores de Agregação e Deslocamento sobre os Símbolos Pontuais.

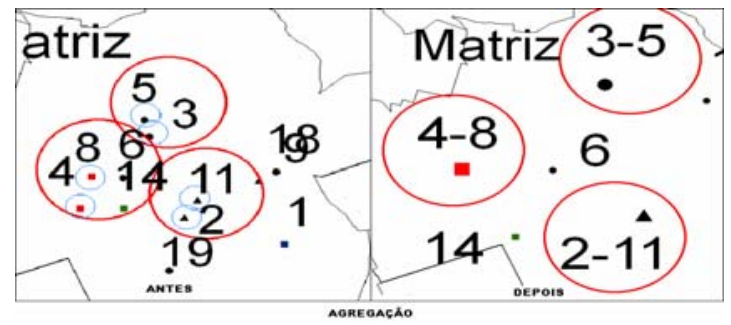

Para os símbolos lineares foram adotados os mesmos critérios e operadores adotados para os pontuais (Figura 3). Mas quando apenas um dos atores da ligação era deslocado foi aplicado o operador de rotação. O segmento de reta era rotacionado tendo como ponto fixo o ator, que não foi deslocado.

Figura 3 - Ação dos Operadores de Generalização sobre os Símbolos Lineares.

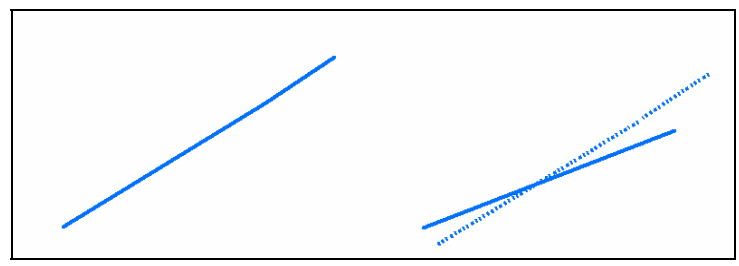

A suavização foi utilizada para retirar a falsa impressão de linhas de divisas mais espessas do que outras (Figura 4). Com a redução de escala, as divisas formadas por corpos d'água pareciam mais espessas. Estas diferenças na espessura induzem o usuário a perceber um nível de medida ordinal ou numérico com relação aos limites entre as regionais de bairro.

Figura 4 - Ação do Operador de Suavização sobre os Limites Regionais.

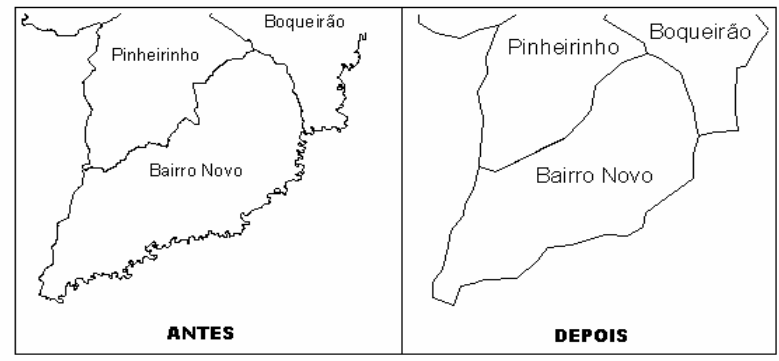

SUA VIZAĞ̈̊

Bol. Ciênc. Geod., sec. Artigos, Curitiba, v. 16, nº 3, p.445-455, jul-set, 2010. 


\subsection{Simbolização}

A definição da linguagem cartográfica é baseada em 3 aspectos dos símbolos que são dependentes entre si, e de acordo com SLOCUM(1999) são: a dimensão espacial da feição e a primitiva gráfica para representá-la; o nível (ou escala) de medida, definido pelas características a serem representadas do fenômeno; e as variáveis visuais das primitivas gráficas, que serão usadas para representar as feições e suas classificações.

A Figura 5 mostra o resultado da simbolização para a classificações dos tipos de organizações. Para diferenciar os diferentes tipos de organização aplicou-se a variável visual forma. A subclassificação para as ONGs foi mostrada variando-se o símbolo por meio do tom de cor. Nos mapas os símbolos maiores do que apresentados na Figura 2 representam aquelas feições que são representantes de mais de um ator social.

Figura 5 - Classificação e Simbologia dos Símbolos Pontuais.

\begin{tabular}{|l|}
\hline ^ Governamental, \\
Movimento Social \\
Não Governamental, Confessional \\
Não Governamental, Empresarial \\
Não Governamental, Filantrópica \\
Não Governamental, Ligada ao Estado \\
Não Governamental, Ligada/Filantrópica \\
Não Governamental, Movimentalista \\
Não Governamental, Outros \\
$\Delta$ Outros, \\
\hline
\end{tabular}

\section{MAPAS RESULTANTES}

A seguir são mostrados quatro mapas, dois antes e dois após a generalização cartográfica da rede social de assistência social com atuação em Curitiba com sede na cidade. A Figura 6 traz os mapas com os tipos de organizações e de ligações. Nota-se que no mapa à esquerda (Figura 6a) há dificuldade de reconhecimento dos atores sociais e suas ligações nas regionais Matriz e Santa Felicidade. A rede pose ser vista com maior detalhamento no mapa da direita (Figura 6b), em que se percebe todas as conexões existentes. Quanto a Figura 7, traz a comparação do mapa de centralidade de grau. Muitas sobreposições de símbolos pontuais ocorreram no mapa da esquerda (Figura 7a). Isto não ocorre no mapa da direita (Figura 7b) porque foi utilizado o operador deslocamento para a representação de todos os atores. 
Figura 6 - Comparação entre os Mapas de Tipo de Organização da Rede Social de Assistência Social na Escala de 1:230.000 antes (a) e após (b) a generalização cartográfica.

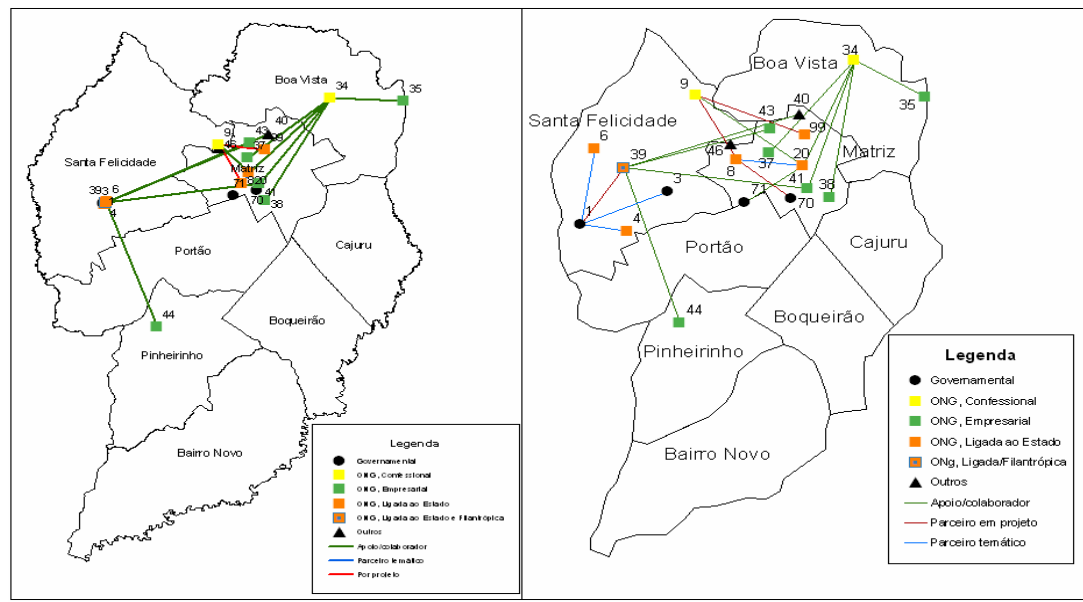

(a)

(b)

Figura 7 - Comparação entre os Mapas de Centralidade de Grau da Rede Social de Assistência Social na Escala de 1:230.000 antes (a) e após (b) a generalização cartográfica.

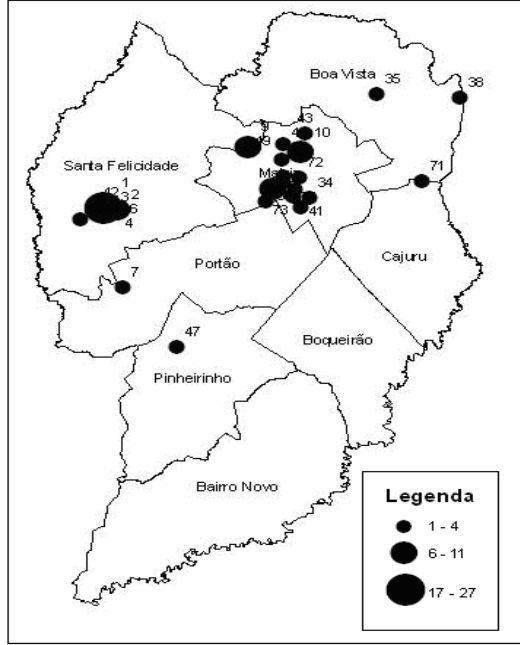

(a)

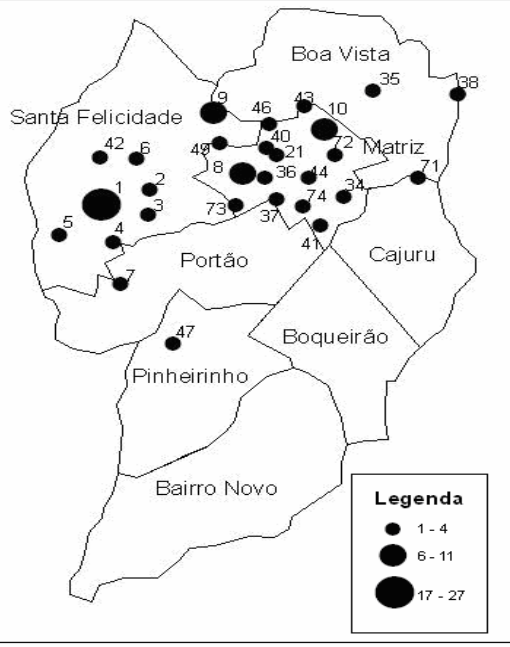

(b)

Bol. Ciênc. Geod., sec. Artigos, Curitiba, v. 16, nº 3, p.445-455, jul-set, 2010. 


\section{CONCLUSÕES}

A contribuição desta pesquisa é relativa à generalização cartográfica para as representações temáticas digitais das redes sociais. Nesta pesquisa foram produzidos nove mapas temáticos generalizados a partir de outros nove mapas originais das redes sociais que foram produzidos em papel. No decorrer do desenvolvimento do projeto cartográfico alguns passos foram importantes para a produção dos mapas como a definição das escalas de representação na tela de um computador com monitor de 15 polegadas, bem como a escolha das projeções cartográficas.

Com a redução da escala, necessária para a representação digital, começaram a surgir problemas de representação como a coalescência. A princípio tentou-se utilizar da classificação já estabelecida por Marchis (2008). No entanto, essas informações tiveram de passar por transformações oriundas da necessidade de generalização gráfica. Logo, a classificação anterior já não era mais adequada aos dados transformados, pois dentre os operadores de generalização aplicados estava o de agregação que, além de generalizar geometricamente, provoca alterações semânticas nos dados.

Os operadores de generalização cartográfica mais utilizados nesta pesquisa foram a agregação, a suavização, a classificação e, sobretudo, o deslocamento. A agregação gerou novos símbolos oriundos da união de dois ou mais símbolos pontuais. A suavização teve como função uniformizar as linhas de fronteira entre as regionais na escala reduzida como função de se retirar do mapa a falsa impressão de ocorrer linhas de divisa mais espessas do que outras. E, por fim, o deslocamento foi utilizado para evitar o congestionamento, a imperceptibilidade e a coalescência entre símbolos pertencentes a diferentes classes. O uso apenas destes operadores bastou para se realizar a generalização cartográfica manual das redes com o objetivo de manter a comunicabilidade.

A aplicação da generalização cartográfica neste trabalho foi feita com o intuito de evidenciar a principal característica das redes sociais que são as ligações, porém com isso perdeu-se alguns comportamentos espaciais dos fenômenos como a representação de concentrações de atores em determinadas regiões. Pois este atores tiveram de ser deslocados para a representação das relações entre si.

Recomenda-se que em próximos estudos sejam desenvolvidos algoritmos para realizar de modo automático ou computacional o posicionamento dos atores.

Ainda se recomenda a avaliação dos mapas por profissionais das áreas de ciências sociais para se obter informações do quanto a interação ajuda no poder de exploração dos dados, bem como avaliar a eficiência dos mapas generalizados.

\section{AGRADECIMENTOS:}

Os pesquisadores agradecem à Universidade Federal do Paraná pelo espaço cedido para a pesquisa. À CAPES pela bolsa auxílio de mestrado disponibilizada. E a todos, que direta ou indiretamente, colaboraram com o trabalho. 
Pombo, R. M. e Sluter, C. R.

\section{REFERÊNCIAS BIBLIOGRÁFICAS}

DELAZARI, L., SLUTER, C., KAUCHAKJE, S. Visualização Cartográfica Aplicada à Análise de Redes Sociais. V Colóquio Brasileiro de Ciências Geodésicas, p 538-542, 2007.

FLEURY, S.; El desafio de la gestión de las redes de políticas. Revista Instituciones e Desarollo, n. 12-13, 2002,p 223.

HANNEMAN, R. RIDDLE M. Introduction to social network methods. Sociology Departament. 2001. http://faculty.ucr.edu/ hanneman/. Acesso em: dez 2007.

KAUCHAKJE, S. et al. Rede sócio-técnica de proteção social: o direito à habitação em Curitiba. 2006.

MACEACHREN, A. M. Some truth with maps: a primer on symbolization and design. 1 ed. AAG. 1994a.

MARCHIS, C. Proposição de projeto cartográfico para representação de redes sociais. Curitiba, 2008. Dissertação de Mestrado - Universidade Federal do Paraná.

MARTELETO, R. M. Análise de redes sociais - aplicação nos estudos de transferência da informação. Ciência da Informação, jan./abr. 2001. $<$ http://www.scielo.br/scielo.php?script=scji_arttext\&pid=S010019652001000100009\&Ing=pt\&nrm=isso $>$ Acesso em 24 jan 2008.

MATHEUS, R. F.; SILVA, A. B. O. Análise de rede social como método para a ciência da informação. Revista de Ciência da Informação, vol. 7, n. 2, 2006. $<$ http://www.netic.com.br/redeci/images/stories/docs/ars.pdf> Acesso em 25 mai 2008.

McMASTER, R.B.; SHEA, K.S. Generalization in Digital Cartography. 1.ed.Washington: Association of American Geographers, 1992. 133p.

MINELLA, A. Tópicos especiais: Introdução à Análise de Redes Sociais. UFSC. Disponível em http://www.sociologia.ufsc.br/programas/spo/spo3711b(2008) html. Acesso em abr 2008.

NALINI, V. Avaliação cartométrica da base cartográfica digital adequada à gestão urbana derivada por generalização cartográfica a partir da escala de origem 1:2000. Curitiba, 2008. Dissertação de Mestrado - Universidade Federal do Paraná.

TOMAÉL, M. I.; MARTELETO, R. M. Redes Sociais: posições dos atores no fluxo da informação. Encontros Bibli., Florianópolis, n.esp., 1. sem. 2006.

(Recebido em agosto de 2009. Aceito em abril de 2010). 